\title{
Transduced Tat-CIAPIN1 reduces the inflammatory response on LPS- and TPA-induced damages
}

\author{
Hyeon Ji Yeo,", Min Jea Shin ${ }^{1, \#}$, Ji Ho You ${ }^{1}$, Jeong Su Kim ${ }^{1}$, Min Young Kim ${ }^{1}$, Dae Won Kim ${ }^{2}$, Duk-Soo Kim ${ }^{3}$, \\ Won Sik Eum ${ }^{1, *}$ E Soo Young Choi ${ }^{1, *}$ \\ ${ }^{1}$ Department of Biomedical Science and Research Institute of Bioscience and Biotechnology, Hallym University, Chuncheon 24252, \\ ${ }^{2}$ Department of Biochemistry and Molecular Biology, Research Institute of Oral Sciences, College of Dentistry, Gangneung-Wonju National \\ University, Gangneung 25457, ${ }^{3}$ Department of Anatomy, College of Medicine, Soonchunhyang University, Cheonan 31538, Korea
}

\begin{abstract}
Cytokine-induced apoptosis inhibitor 1 (CIAPIN1), known as an anti-apoptotic and signal-transduction protein, plays a pivotal role in a variety of biological processes. However, the role of CIAPIN1 in inflammation is unclear. We investigated the protective effects of CIAPIN1 in lipopolysaccharide (LPS)-exposed Raw 264.7 cells and against inflammatory damage induced by 12-O-tetradecanoylphorbol-13-acetate (TPA) in a mouse model using cell-permeable Tat-CIAPIN1. Transduced Tat-CIAPIN1 significantly reduced ROS production and DNA fragmentation in LPS-exposed Raw 264.7 cells. Also, TatCIAPIN1 inhibited MAPKs and NF-KB activation, reduced the expression of Bax, and cleaved caspase-3, COX-2, iNOS, IL-6, and TNF- $\alpha$ in LPS-exposed cells. In a TPA-induced animal model, transduced Tat-CIAPIN1 drastically decreased inflammation damage and inhibited COX-2, iNOS, IL-6, and TNF- $\alpha$ expression. Therefore, these findings suggest that Tat-CIAPIN1 might lead to a new strategy for the treatment of inflammatory skin disorders. [BMB Reports 2019; 52(12): 695-699]
\end{abstract}

\section{INTRODUCTION}

Inflammation is a natural defense response to infection or injury, and it may lead to various human diseases, including cancer (1). Under the inflammatory responses, macrophages are activated and secrete pro-inflammatory mediator proteins, such as cyclooxygenase-2 (COX-2), inducible nitric oxide

*Corresponding authors. Soo Young Choi, Tel: +82-33-248-2112; Fax: +82-33-248-3202; E-mail: sychoi@hallym.ac.kr; Won Sik Eum, Tel: +82-33-248-3221; Fax: +82-33-248-3202; E-mail: wseum@ hallym.ac.kr

${ }^{\text {\#}}$ These authors contributed equally to this work.

https://doi.org/10.5483/BMBRep.2019.52.12.245

Received 14 October 2019, Revised 16 October 2019, Accepted 21 October 2019

Keywords: Cytokine, Inflammation, MAPK, Protein therapy, TatCIAPIN1 synthase (iNOS), and reactive oxygen species (ROS) as well as pro-inflammatory cytokines, including interleukin (IL)-6, IL-1 $\beta$, and tumor necrosis factor- $\alpha$ (TNF- $\alpha)$ (2-5). Several studies have demonstrated that the nuclear factor-kappa $\mathrm{B}(\mathrm{NF}-\mathrm{\kappa B})$ and the mitogen-activated protein kinases (MAPKs) signaling pathways play a pivotal role in inflammatory responses, suggesting that

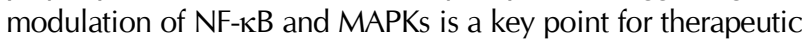
approaches to inflammatory diseases (6-10).

Cytokine-induced apoptosis inhibitor 1 (CIAPIN1) is known as an anti-apoptotic and signal-transduction protein, and many studies have revealed that CIAPIN1 may suppress apoptosis and regulate tumorigenesis (11-14). Park et al. (2011) reported that the CIAPIN1 protein protects neuronal MN9D cells against oxidative stress-induced cell death by increasing the expression of anti-apoptotic proteins (15). Wang et al. (2015) have shown that transfected CIAPIN1 genes in human multiple myeloma significantly inhibited the growth and proliferation of tumor cells, suggesting that CIAPIN1 is a potential tumor suppressor (16) and several studies have reported that chronic inflammation can lead to cancer by increasing pro-inflammatory mediators, ROS, intracellular signaling-pathway mediators, and transcription factors (17-19). Although the CIAPIN1 protein may be associated with the suppression of cancer and inflammation, there is no evidence about its exact roles in inflammation until now. Therefore, we investigated the effects of Tat-CIAPIN1 on inflammation with lipopolysaccharide (LPS)-exposed Raw 264.7 cells and a 12-O-tetradecanoylphorbol13-acetate (TPA)-induced mouse edema model.

\section{RESULTS AND DISCUSSION}

Transduction and effects of Tat-CIAPIN1 against LPS-induced cytotoxicity in Raw 264.7 cells

Since it is known that protein transduction domains (PTDs) can deliver proteins into cells, many studies have suggested that PTDs can be used for application of therapeutic proteins to treat various diseases (20-30). Purified Tat-CIAPIN1 protein was identified (Supplementary Fig. S1). We showed that Tat-CIAPIN1 transduced into the Raw 264.7 cells concentrationand time-dependently as well as transduced Tat-CIAPIN1

ISSN: 1976-670X (electronic edition)

Copyright (c) 2019 by the The Korean Society for Biochemistry and Molecular Biology

(c) This is an open-access article distributed under the terms of the Creative Commons Attribution Non-Commercial License (http://creativecommons.org/licenses/by-nc/4.0) which permits unrestricted non-commercial use, distribution, and reproduction in any medium, provided the original work is properly cited. 
levels persisted in the cells for $12 \mathrm{~h}$ (Supplementary Fig. S2A-S2C).

We also assessed the distribution of Tat-CIAPIN1 in Raw 264.7 cells using immunostaining with Alexa Fluor 488 and DAPI. Tat-CIAPIN1 transduced into both the cytosol and the nuclei of Raw 264.7 cells. However, CIAPIN1 did not transduce into the cells (Fig. 1A). Other studies have reported that LPS induces ROS production and DNA damage in various cells, including Raw 264.7 cells, finally leading to cell damage $(2-4,31)$. In agreement with these reports, we showed that ROS generation and DNA fragmentation levels were significantly increased in the cells exposed only to LPS, control CIAPIN1, and Tat peptide. However, transduced Tat-CIAPIN1 markedly inhibited ROS generation and DNA fragmentation in LPS-exposed cells (Fig. 1B and 1C).

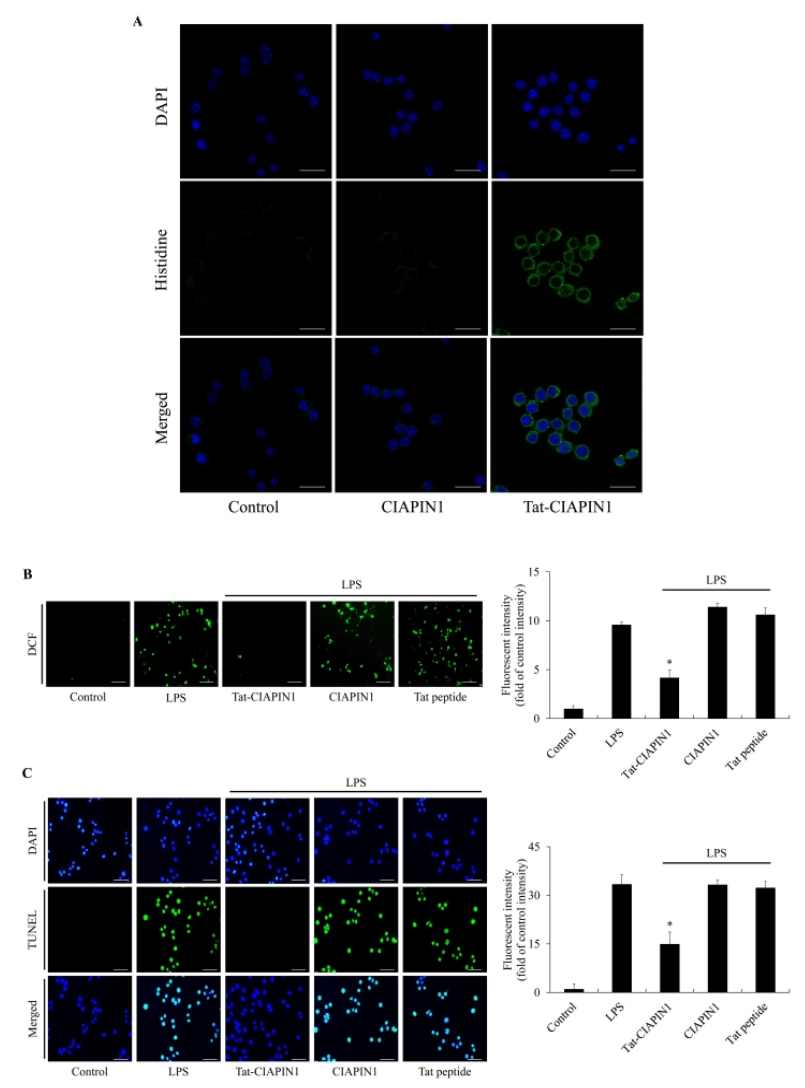

Fig. 1. Effects of transduced Tat-CIAPIN1 protein on LPS-induced ROS production and DNA fragmentation. The localization of transduced Tat-CIAPIN1 protein was examined by confocal fluorescence microscopy (A). Scale bar $=20 \mu \mathrm{m}$. Cells were treated with Tat-CIAPIN1 $(3 \mu \mathrm{M})$ or CIAPIN1 protein for $1 \mathrm{~h}$ before treatment with $1 \mu \mathrm{g} / \mathrm{ml}$ of LPS for $3 \mathrm{~h}$ or $14 \mathrm{~h}$. Then, intracellular ROS levels (B) and DNA fragmentation (C) were measured by DCF-DA staining and TUNEL staining. Fluorescence intensity was quantified using an ELISA plate reader. Scale bar = $50 \mu \mathrm{m}$. $* \mathrm{P}<0.05$, compared with LPS-treated cells.

\section{Effects of Tat-CIAPIN1 on LPS-induced inflammatory} responses in Raw 264. 7 cells

Other studies have reported that regulation of $\mathrm{NF}-\mathrm{kB}$ and MAPKs signaling pathways are important to protect against LPS-induced inflammatory responses in Raw 264.7 cells (32, 33). To examine the effects of Tat-CIAPIN1 on LPS-induced signaling pathways (MAPKs and NF- $\mathrm{kB}$ ), the cells were exposed to LPS $(1 \mu \mathrm{g} / \mathrm{ml})$. In the LPS-exposed cells, phosphorylated MAPKs and p65 expression were higher than in the control cells. CIAPIN1 and Tat peptide-exposed cells showed similar patterns. In contrast, Tat-CIAPIN1 significantly reduced the phosphorylated MAPKs and p65 expression (Fig. 2A). Many studies have described that NF- $\mathrm{KB}$ and MAPKs signaling pathways are crucial mediators in various cellular biological processes and play a key role in the process of inflammatory
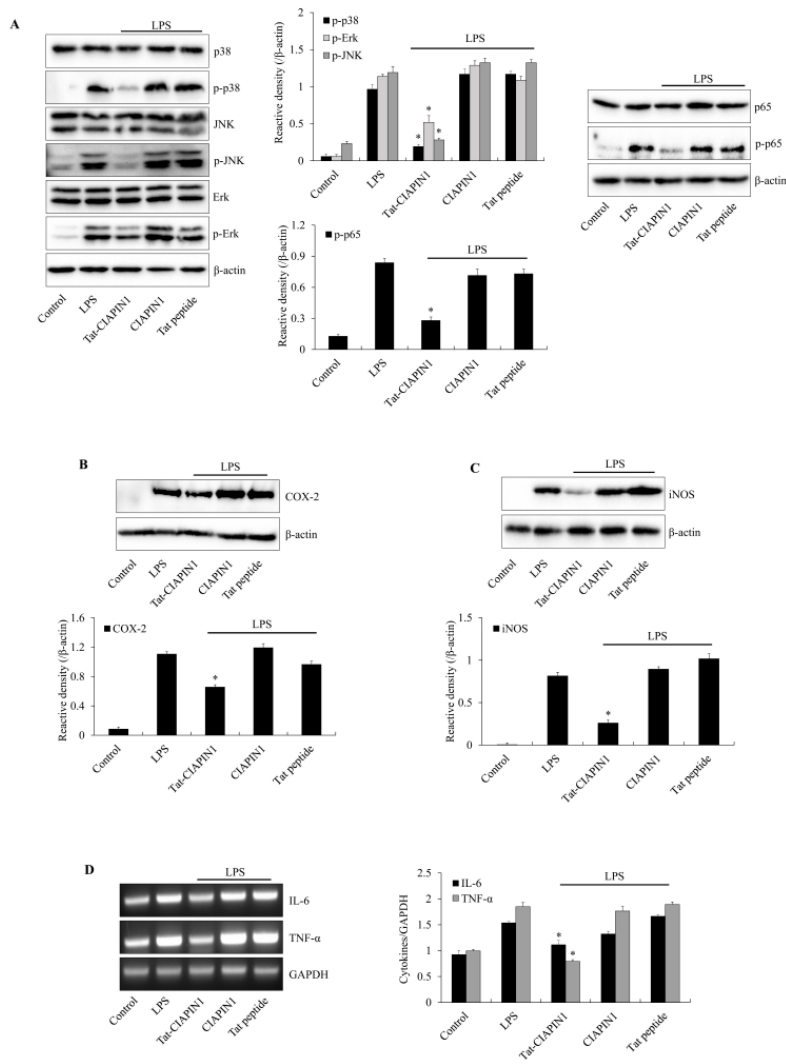

Fig. 2. Effects of Tat-CIAPIN1 protein on LPS-induced inflammatory responses in Raw 264.7 cells. The cells were treated with Tat-CIAPIN1 $(3 \mu \mathrm{M})$ or CIAPIN1 protein for $1 \mathrm{~h}$ before being exposed to LPS $(1 \mu \mathrm{g} / \mathrm{ml})$. MAPK and NF- $\kappa$ B activation (A) and the expression levels of COX-2 (B) and iNOS (C) protein were analyzed by Western blotting. Total RNA was extracted from the cells. We analyzed cytokines (IL-6 and TNF- $\alpha$ ) and GAPDH mRNA by RT-PCR using specific indicated primers (D). The band intensity was measured by densitometer. ${ }^{*} P<0.05$, compared with LPS-treated cells. 
response by promoting the release of the pro-inflammatory cytokines (34-36).

We investigated the effect of Tat-CIAPIN1 against LPS-induced Bax, Bcl-2, and Caspase-3 expression levels. Other studies have shown that LPS induced apoptosis via a caspasedependent mitochondrial death signaling pathway $(37,38)$. Supplementary Fig. S3A-S3C shows that Bcl-2 and Caspase-3 expression were reduced in the LPS-exposed Raw 264.7 cells. However, Tat-CIAPIN1 significantly increased $\mathrm{BCl}-2$ and Caspase-3 expression more than did those treated with LPS alone. In contrast, Bax and cleaved Caspase-3 expression showed an effect opposite to that of $\mathrm{BCl}-2$ and Caspase-3. There was no changes in CIAPIN1 and Tat peptide-treated cells. Consistent with our results, other studies have shown that overexpression of CIAPIN1 reduced cleaved Caspase-3 expression, whereas Caspase-3 expression was increased in CIAPIN1-depleted K562 cells, suggesting that CIAPIN1 has an anti-apoptotic function $(39,40)$. In addition, CIAPIN1 protected against neuronal cell death caused by increased $\mathrm{Bcl}-\mathrm{XL}$ under oxidative stress conditions, suggesting that CIAPIN1 plays an important role in protecting neuronal cells against cell death induced by oxidative stress (15).

We also investigated whether Tat-CIAPIN1 suppresses the inflammatory response in LPS-induced Raw 264.7 cells. LPS
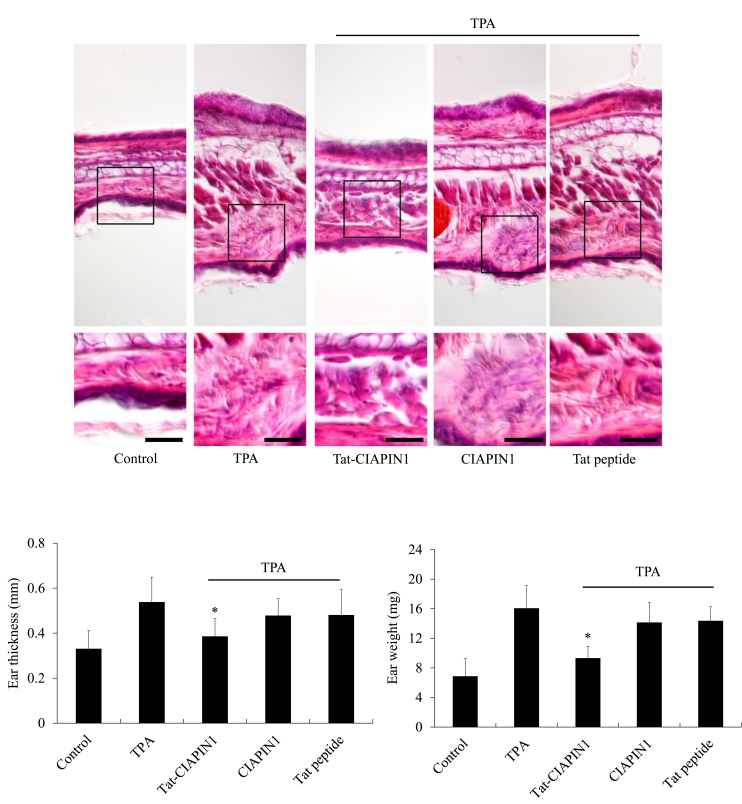

Fig. 3. Effects of Tat-CIAPIN1 protein on TPA-induced mice ear edema. Ears of mice were treated with TPA (1 $\mu \mathrm{g} / \mathrm{ear})$ once a day for 3 days. Tat-CIAPIN1 protein $(10 \mu \mathrm{g})$ was topically applied to the mouse ears $1 \mathrm{~h}$ prior to TPA exposure over 3 days. Protective effects of Tat-CIAPIN1 protein were confirmed by hematoxylin and eosin staining, changes in ear weight, and ear thickness in a TPA-induced mice ear edema model. Scale bar = $50 \mu \mathrm{m} .{ }^{*} \mathrm{P}<0.05$, compared with TPA-treated mice. markedly increased COX-2, iNOS, TNF- $\alpha$, and IL- 6 expression in Raw 264.7 cells. There were no changes in CIAPIN1 and Tat peptide-treated cells. However, Tat-CIAPIN1 drastically reduced COX-2, iNOS, TNF- $\alpha$, and IL- 6 expression in LPS-exposed Raw 264.7 cells (Fig. 2B-2D). Several studies have reported that LPS activated macrophages via the activation of NF- $\mathrm{KB}$, MAPKs, pro-inflammatory proteins, and cytokines and led to cell death $(32,33,41-43)$. These data indicate that Tat-CIAPIN plays an important role against LPS-induced Raw 264.7 cell injury. However, the precise mechanism involved in the target site of Tat-CIAPIN1 in inflammatory molecular signal pathways remains to be elucidated.
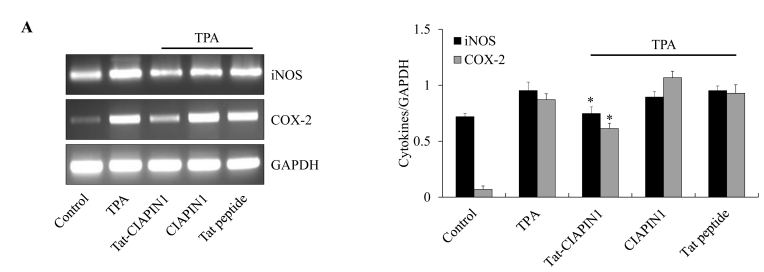

B
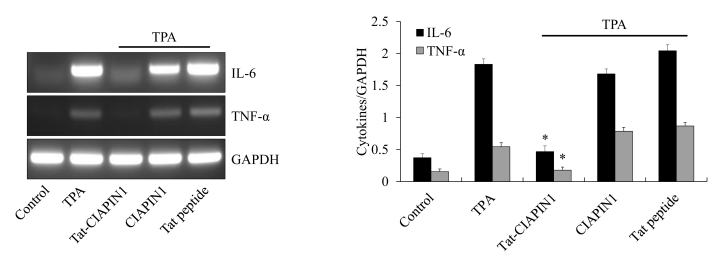

C
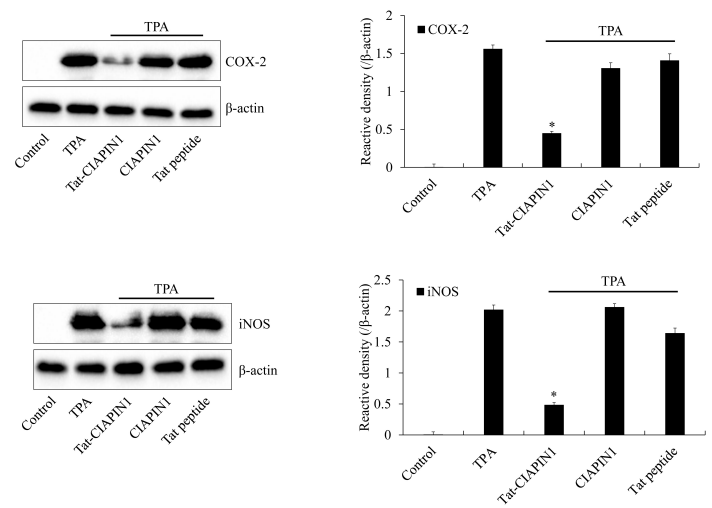

Fig. 4. Effects of Tat-CIAPIN1 protein on TPA-induced pro-inflammatory mediator protein (iNOS and COX-2) and cytokine (IL-6 and TNF- $\alpha$ ) expression in mice ears. Mice were stimulated with TPA (1 $\mu \mathrm{g} / \mathrm{ear})$, after which Tat-CIAPIN1 protein $(10 \mu \mathrm{g})$ was topically applied to the mouse ears for 3 days. Mouse ear extracts were prepared. After total RNA was extracted from ear biopsies, pro-inflammatory mediator proteins (iNOS and COX-2) and cytokine (IL-6 and TNF- $\alpha$ ) expression levels were measured by RT-PCR using specific primers (A, B). The expression levels of pro-inflammatory mediator protein (iNOS and COX-2) were confirmed by Western blotting $(C, D)$. The band intensity was measured by densitometer. ${ }^{*} P<0.05$, compared with TPA-treated mice. 


\section{Effects of Tat-CIAPIN1 on TPA-induced ear edema model} It has been reported that multiple applications of TPA to the ears of mice induce skin inflammation (44). TPA-induced skin tumors are highly related to the inflammatory response, including production of cytokines, iNOS, and COX-2 proteins (45-48). Therefore, we investigated whether transduced Tat-CIAPIN1 protects against inflammation in a TPA-induced ear edema animal model (Supplementary Fig. S4). As shown in Fig. 3, TPA significantly increased ear thickness and weight of mice as compared with the control-, CIAPIN1- and Tat peptide-treated groups. This increase in ear thickness and weight was markedly inhibited by treatment with Tat-CIAPIN1. We also examined whether Tat-CIAPIN1 could inhibit expression of pro-inflammatory cytokines and proteins. TPA markedly increased the COX-2, iNOS, TNF- $\alpha$, and IL-6 expression in mice ears. CIAPIN1 and Tat peptide did not show the protective effects. However, Tat-CIAPIN1 drastically reduced the COX-2, iNOS, TNF- $\alpha$, and IL- 6 expression in a TPA-induced mice model of edema (Fig. 4). Our results coincide with those of Chung et al. (2007), who reported that pro-inflammatory protein and cytokines expression markedly increased in TPA-induced skin inflammation models (49).

In summary, our study showed that Tat-CIAPIN1 inhibits LPS-induced inflammation damage by suppression of pro-inflammatory proteins and cytokines expression and of the NF-kB and MAPK signaling pathways. These finding imply that Tat-CIAPIN1 exerts a protective role in the inflammatory response. Although further studies are still needed to confirm the precise roles of Tat-CIAPIN1 in inflammation, these finding suggest that Tat-CIAPIN1 may be a potential therapeutic agent for skin inflammatory diseases.

\section{MATERIALS AND METHODS}

See supplementary information for this section.

\section{ACKNOWLEDGEMENTS}

This research was supported by the Basic Science Research Program (2017R1D1A3B04032007 \& 2019R1A6A1A11036849) through the National Research Foundation of Korea (NRF) funded by the Ministry of Education.

\section{CONFLICTS OF INTEREST}

The authors have no conflicting interests.

\section{REFERENCES}

1. Fan G, Jiang X, Wu X et al (2016) Anti-inflammatory activity of Tanshinone IIA in LPS-stimulated RAW264.7 macrophages via miRNAs and TLR4-NF-kappaB pathway. Inflammation 39, 375-384

2. Duffield JS (2003) The inflammatory macrophage: a story of Jekyll and Hyde. Clin Sci 104, 27-38

3. Fujihara M, Muroi M, Tanamoto K, Suzuki T, Azuma $\mathrm{H}$ and Ikeda H (2003) Molecular mechanisms of macrophage activation and deactivation by lipopolysaccharide: roles of the receptor complex. Pharmacol Ther 100, 171-194

4. Chung HY, Cesari M, Anton S et al (2009) Molecular inflammation as an underlying mechanism of aging: the anti-inflammatory action of calorie restriction. Ageing Res Rev 8, 18-30

5. Korhonen R, Lahti A, Kankaanranta $\mathrm{H}$ and Moilanen $\mathrm{E}$ (2005) Nitric oxide production and signaling in inflammation. Curr Drug Targets Inflamm Allergy 4, 471-479

6. Grilli M and Memo M (1999) Possible role of NF-kappaB and p53 in the glutamate-induced pro-apoptotic neuronal pathway. Cell Death Differ 6, 22-27

7. Lawrence T, Gilroy DW, Colville-Nash PR and Willoughby DA (2001) Possible new role for NF-kB in the resolution of inflammation. Nat Med 7, 1291-1297

8. Riehemann K, Behnke B and Schulze-Osthoff K (1999) Plant extracts from stinging nettle (Urtica dioica), an antirheumatic remedy, inhibit the proinflammatory transcription factor NF-kB. FEBS Lett 442, 89-94

9. Ivashkiv LB (2011) Inflammatory signaling in macrophages: transitions from acute to tolerant and alternative activation states. Eur J Immunol 41, 2477-2481

10. Sica A and Mantovani A (2012) Macrophage plasticity and polarization: in vivo veritas. J Clin Invest 122, 787-795

11. Shibayama H, Takai E, Matsumura I et al (2004) Identification of a cytokine-induced antiapoptotic molecule anamorsin essential for definitive hematopoiesis. J Exp Med 199, 581-592

12. Li X, Wu K and Fan D (2010) CIAPIN1 as a therapeutic target in cancer. Expert Opin Ther Targets 14, 603-610

13. Hao Z, Li X, Qiao T, Du R, Hong L and Fan D (2006) CIAPIN1 confers multidrug resistance by upregulating the expression of MDR-1 and MRP-1 in gastric cancer cells. Cancer Biol Ther 5, 261-266

14. Li X, Fan R, Zou X et al (2008) Reversal of multidrug resistance of gastric cancer cells by down-regulation of CIAPIN1 with CIAPIN1 siRNA. Mol Biol 42, 102-109

15. Park KA, Yun N, Shin Dl et al (2011) Nuclear translocation of anamorsin during drug-induced dopaminergic neurodegeneration in culture and in rat brain. J Neural Transm 118, 433-444

16. Wang X, Pan J and Li J (2015) Cytokine-induced apoptosis inhibitor 1 inhibits the growth and proliferation of multiple myeloma. Mol Med Res 12, 2056-2062

17. Sethi G, Shanmugam MK, Ramachandran L, Kumar AP and Tergaonkar V (2012) Multifaceted link between cancer and inflammation. Biosci Rep 32, 1-15

18. Sethi G and Tergaonkar V (2009) Potential pharmacological control of the NF-kappaB pathway. Trends Pharmacol Sci 30, 313-321

19. Lemmon MA and Schlessinger J (2010) Cell signaling by receptor tyrosine kinases. Cell 141, 1117-1134

20. El-Andaloussi S, Holm T and Langel U (2005) Cell-penetrating peptides: mechanisms and applications. Curr Pharm Des 11, 3597-3611

21. Wadia JS and Dowdy SF (2002) Protein transduction 
technology. Curr Opin Biotechnol 13, 52-56

22. Ramsey JD and Flynn NH (2015) Cell-penetrating peptides transport therapeutics into cells. Pharmacol Ther 54, 78-86

23. Zhang X, Li Y, Cheng Y et al (2015) Tat PTD-endostatin: A novel anti-angiogenesis protein with ocular barrier permeability via eye-drops. Biochim Biophys Acta 1850, 1140-1149

24. Sakurazawa $M$, Katsura K, Saito $M$, Asoh S, Ohta $S$ and Katayama Y (2012) Mild hypothermia enhanced the protective effect of protein therapy with transductive anti-death FNK protein using a rat focal transient cerebral ischemia model. Brain Res 1430, 86-92

25. Kim MJ, Park M, Kim DW et al (2015) Transduced PEP-1-PON1 proteins regulate microglial activation and dopaminergic neuronal death in a Parkinson's disease model. Biomaterials 64, 45-56

26. Kim MJ, Kim DW, Park JH et al (2013) PEP-1-SIRT2 inhibits inflammatory response and oxidative stress-induced cell death via expression of antioxidant enzymes in murine macrophages. Free Radic Biol Med 63, 432-445

27. Shin MJ, Kim DW, Lee YP et al (2014) Tat-glyoxalase protein inhibits against ischemic neuronal cell damage and ameliorates ischemic injury. Free Radic Biol Med 67, 195-210

28. Yeo HJ, Shin MJ, Yeo EJ et al (2019) Tat-CIAPIN1 inhibits hippocampal neuronal cell damage through the MAPK and apoptotic signaling pathways. Free Radic Biol Med $135,68-78$

29. Moon JI, Han MJ, Yu SH et al (2019) Enhanced delivery of protein fused to cell penetrating peptides to mammalian cells. BMB Rep 52, 324-329

30. Yeo HJ, Yeo EJ, Shin MJ et al (2018) Protective effects of Tat-DJ-1 protein against streptozotocin-induced diabetes in a mice model. BMB Rep 51, 362-367

31. Jaiswal $Y K$, Jaiswal MK, Agrawal $V$ and Chaturvedi $M M$ (2009) Bacterial endotoxin (LPS)-induced DNA damage in preimplanting embryonic and uterine cells inhibits implantation. Fertil Steril 91, 2095-2103

32. Uto $T$, Suangkaew $N$, Morinaga $\mathrm{O}$, Kariyazono $\mathrm{H}$, Oiso $\mathrm{S}$ and Shoyama Y (2010) Eriobotryae folium extract suppresses LPS-induced iNOS and COX-2 expression by inhibition of NF-kappaB and MAPK activation in murine macrophages. Am J Chin Med 38, 985-994

33. Gao Y, Jiang W, Dong C et al (2012) Anti-inflammatory effects of sophocarpine in LPS-induced RAW 264.7 cells via NF- $\kappa B$ and MAPKs signaling pathways. Toxicol In Vitro 26, 1-6

34. Cao F, Liu T, Xu Y, Xu D and Feng S (2015) Curcumin inhibits cell proliferation and promotes apoptosis in human osteoclastoma cell through MMP-9, NF- $\mathrm{kB}$ and JNK signaling pathways. Int J Clin Exp Pathol 8, 60376045

35. Kim KN, Heo SJ, Yoon WJ et al (2010) Fucoxanthin inhibits the inflammatory response by suppressing the activation of NF- $\mathrm{\kappa B}$ and MAPKs in lipopolysaccharideinduced RAW 264.7 macrophages. Eur J Pharmacol 649, 369-375
36. Ki YW, Park JH, Lee JE, Shin IC and Koh HC (2013) JNK and p38 MAPK regulate oxidative stress and the inflammatory response in chlorpyrifos-induced apoptosis. Toxicol Lett 218, 235-245

37. Barton GM and Medzhitov R (2003) Toll-like receptor signaling pathways. Science 300, 1524-1525

38. Langford MP, McGee DJ, Ta KH, Redens TB and Texada DE (2011) Multiple caspases mediate acute renal cell apoptosis induced by bacterial cell wall components. Ren Fail 33, 192-206

39. Yun N, Lee YM, Kim C et al (2014) Anamorsin, a novel caspase-3 substrate in neurodegeneration. J Biol Chem 289, 22183-22195

40. Wang J, Li Q, Wang C et al (2016) Knock-down of CIAPIN1 sensitizes K562 chronic myeloid leukemia cells to Imatinib by regulation of cell cycle and apoptosisassociated members via NF-kB and ERK5 signaling pathways. Biochem Pharmacol 99, 132-145

41. Fujihara M, Muroi M, Tanamoto K, Suzuki T, Azuma H and Ikeda H (2003) Molecular mechanisms of macrophage activation and deactivation by lipopolysaccharide: roles of the receptor complex. Pharmacol Ther 100, 171-194

42. Khan S, Shin EM, Choi RJ et al (2011) Suppression of LPS-induced inflammatory and NF- $\mathrm{BB}$ responses by anomalin in RAW 264.7 macrophages. J Cell Biochem $112,2179-2188$

43. Su YW, Chiou WF, Chao SH, Lee MH, Chen CC and Tsai YC (2011) Ligustilide prevents LPS-induced iNOS expression in RAW 264.7 macrophages by preventing ROS production and down-regulating the MAPK, NF- $\mathrm{KB}$ and AP-1 signaling pathways. Int Immunopharmacol 11, 1166-1172

44. Stanley PL, Steiner S, Havens $M$ and Tramposch KM (1991) Mouse skin inflammation induced by multiple topical applications of 12-O-tetradecanoylphorbol-13-acetate. Skin Pharmacol 4, 262-271

45. Hoffmann A and Baltimore D (2006) Circuity of nuclear factor kappaB signaling. Immunol Rev 210, 171-186

46. Baud V and Karin M (2009) Is NF-kappaB a good target for cancer therapy? Hopes and pitfalls. Nat Rev Drug Discovery 8, 33-40

47. Kundu JK, Shin YK and Surh YJ (2006) Resveratrol modulates phorbol ester-induced pro-inflammatory signal transduction pathways in mouse skin in vivo: NF-kappaB and AP-1 as prime targets. Biochem Pharmacol 72, 1506-1515

48. Murakami A, Nakamura Y, Torikai K et al (2000) Inhibitory effect of citrus nobiletin on phorbol esterinduced skin inflammation, oxidative stress, and tumor promotion in mice. Cancer Res 60, 5059-5066

49. Chung WY, Park JH, Kim MJ et al (2007) Xanthorrhizol inhibits 12-O-tetradecanoylphorbol-13-acetate-induced acute inflammation and two-stage mouse skincarcinogenesis by blocking the expression of ornithine decarboxylase, cyclooxygenase-2 and inducible nitric oxide synthase through mitogen-activated protein kinases and/or the nuclear factor-kappa B. Carcinogen 28, 1224-1231 